\title{
Amaranth Leaf Extract Protects Against Hydrogen Peroxide Induced Oxidative Stress in Drosophila Melanogaster
}

Johnmark Ndinawe

Kampala International University

Hellen W. Kinyi ( $\nabla$ hkinyi@kab.ac.ug )

Kabale University https://orcid.org/0000-0002-8007-3618

\section{Research note}

Keywords: Oxidative stress, Amaranths, Drosophila melanogaster, Antioxidants

Posted Date: March 19th, 2021

DOI: https://doi.org/10.21203/rs.3.rs-322299/v1

License: (c) (i) This work is licensed under a Creative Commons Attribution 4.0 International License.

Read Full License 


\section{Abstract}

\section{Objective}

Amaranths leaves are rich in ascorbic acid and polyphenol compounds which have antioxidant activity. The aim of this study was to evaluate their in vivo antioxidant activity. The effect of consumption of Amaranth leaf extract on in vivo antioxidant activity, catalase enzyme activity and $\mathrm{H}_{2} \mathrm{O}_{2}$ induced oxidative stress in Drosophila melanogaster flies was assessed.

\section{Results}

Consumption of Amaranth leaf extract was associated with increased survival on exposure to $\mathrm{H}_{2} \mathrm{O}_{2}$ in a dose dependent manner in Drosophila melanogaster flies.

\section{Introduction}

Oxidative stress refers to an imbalance arising due to excess production of free radicals and reduced activity of antioxidants. Free radicals are atoms or molecules that contain unpaired electrons and react with other molecules by taking or giving electrons (1). They can be products of normal cellular metabolism or environmental stressors and have been implicated in the pathogenesis of many diseases $(2,3)$.

Antioxidant compounds neutralize harmful effects of free radicals by either preventing their formation or removing them before they can cause damage to cellular structures (4). Consumption of fruits and vegetables rich in antioxidants has been linked to reduction in the incidence of oxidative-stress related diseases such as; cancer, diabetes, neurodegenerative diseases, inflammation as well as cell and cutaneous aging issues (5).

Amaranths, the generic name by which the vegetables of the genus Amaranthus are referred to are widely distributed short-lived herbs that occur in temperate and tropical regions. The Amaranthus species is one of the few plants from which leaves are eaten as a vegetable while the seeds are eaten as cereals(6). The in vitro antioxidant activity of Amaranths leaves has been well documented and attributed to both vitamin $C$ and polyphenol compounds found in extracts (7-9) The specific objective of this work was to evaluate the in vivo antioxidant protective activity of Amaranths in a Drosophila melanogastermodel of oxidative stress.

\section{Main Text}

\section{Methods}

The model used for the study was the $w^{1118}$ (white) strain of Drosophila melanogaster, a gift from Dr. Isabel Palacios (UK) and maintained at the Institute of Biomedical Research, Kampala International 
University Western Campus, Ishaka-Bushenyi, Uganda. They were fed on cornmeal-yeast-agar medium (10) and maintained at $25^{\circ} \mathrm{C}$ under a $12 / 12$ hour light and dark cycle in a digital fly incubator. From the stock population, virgin females and young males were placed on fresh food and allowed to mate. Fresh eggs were collected, and dated to ensure that the dates of birth are synchronized for all flies. From these, 360 male adult flies were collected and divided into 3 groups to be fed on: normal food (NF), Amaranth extract, and ascorbic acid (ASA) groups. The NF (180 flies), was fed on the standard cornmeal diet, the Amaranth group (180 flies) fed on the Amaranth-fly food mixture and ASA group on ASA-fly food mixture. To determine the in vivo antioxidant activity, catalase enzyme activity and resistance to oxidative stress, groups of Drosophila flies were fed on the respective diets for 5 days (11).

\section{Preparation of experimental food}

Amaranth leaves used in the study were purchased from a vendor in the Central market of Ishaka town of Bushenyi Municipality of Western Uganda. Extraction was done as previously described (12). To prepare the fly food with Amaranth and ascorbic acid, $0.25 \mathrm{mg}$ and $0.5 \mathrm{mg}$ of Amaranth extract and ascorbic acid were each dissolved in $10 \mathrm{mls}$ of distilled water to obtain a concentration of $2.5 \mathrm{mg} / \mathrm{ml}$ and $5 \mathrm{mg} / \mathrm{ml}$ respectively. Each was separately added to $490 \mathrm{mls}$ of molten fly food and mixed thoroughly to obtain a mixture with Amaranth extract and Ascorbic acid each at a concentration of $0.05 \mathrm{mg} / \mathrm{ml}$ and $0.1 \mathrm{mg} / \mathrm{ml}$. These mixtures were then poured in labeled vials and left to cool. The food was covered with cotton balls and stored at $4^{0} \mathrm{C}$.

\section{Determination ofin vivoantioxidant activity}

Ten flies each from the NF, Amaranth and ASA groups were separately anaesthetized on ice and homogenized in $100 \mu \mathrm{l}$ of cold $0.05 \%$ phosphate buffered saline tween (PBST) solution ( $\mathrm{pH} 7.4$ ). The homogenate was centrifuged at $4000 \mathrm{~g}$ for 10 minutes and the supernatant collected and used for the determination of 2, 2-diphenyl-1-picrylhydrazyl radical (DPPH) scavenging activity. DPPH scavenging

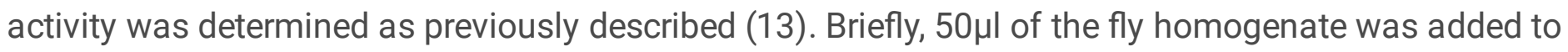
$5 \mathrm{mls}$ of $0.004 \%$ methanol solution of DPPH. This mixture was incubated in the dark at room temperature for 30 minutes. The absorbance of the mixture was then read at $517 \mathrm{~nm}$ against a DPPH blank. The assay was carried out in triplicate and percentage of inhibition was calculated using the formula:

$\%$ Inhibition $=[(A B-A A) / A B] * 100$

Where $A B=$ Absorbance of blank; $A A=$ Absorbance of test.

\section{Determination of resistance to hydrogen peroxide induced oxidative stress}

The resistance to hydrogen peroxide-induced oxidative stress was conducted as previously described with minor modifications (14). Briefly, ten fruit flies from each of the NF, Amaranth and ASA groups were transferred to empty vials after 5 days of feeding. The flies were starved for 6 hours to stimulate the 
uptake of hydrogen peroxide. Afterwards, the flies were transferred to vials containing only filter paper soaked with $1 \%$ hydrogen peroxide in $5 \%$ sucrose solution. Flies alive/dead were recorded every day until the last one died.

\section{Catalase enzyme activity}

The assay was carried out on Drosophila flies fed on the NF, Amaranth and ASA food for five days. Ten flies per group anaesthetized by chilling on ice were homogenized in ice cold phosphate buffer saline $(\mathrm{pH}$ 7.4) and centrifuged at 2,500 rpm for 10 minutes. The resulting supernatant was collected and used for the catalase assay. The catalase activity was measured as previously described (15).

\section{Statistical Analysis}

Data was analyzed using the free software Paleontological statistics software (PAST 3), expressed as mean and standard deviation and presented as graphs.

Data of DPPH scavenging and catalase activities were analyzed using factorial analysis of variance (ANOVA) followed by a Tukey's multiple comparison test.

Oxidative stress resistance was determined using Kaplan-Meier survival analysis with significance set at $\mathrm{P}<0.05$.

\section{Results}

Homogenates from flies fed on food containing Amaranth or ascorbic acid at $0.05 \mathrm{mg} / \mathrm{ml}$ respectively had significantly higher DPPH scavenging activity compared to homogenates from flies fed on normal food as shown in Fig. 1. However, the increase was not significant at $0.1 \mathrm{mg} / \mathrm{ml}$ of Amaranth extract. The increase was similar to that observed when supplementing food with ascorbic acid.

There was no significant increase in catalase activity in Drosophila flies fed on food supplemented with Amaranth leaf extract.

Supplementing food with Amaranth extract improved survival of flies exposed to $\mathrm{H}_{2} \mathrm{O}_{2}$ in a dose dependent manner. The improvement at $0.1 \mathrm{mg} / \mathrm{ml}$ was statistically significant and similar to the protection offered by the antioxidant ascorbic acid.

\section{Discussion}

Green leafy vegetables such as Amaranths contain antioxidant vitamins including ascorbic acid, atocopherol and $\beta$-carotene. However, most of their antioxidant activity is from polyphenol compounds such as flavonoids, isoflavones, flavones, anthocyanins, catechin and isocatechin (16-18). Intake of compounds containing exogenous antioxidants is associated with an enhancement of endogenous antioxidant defenses $(9,11)$. This has also been seen in this study with the increase in the in vivo DPPH free radical scavenging activity seen in Drosophila flies fed on Amaranth leaf extracts. Exogenous 
antioxidants can also modulate endogenous enzyme activity (5). For example, catalase activity is increased in Drosophila flies fed on mango tree leaf extracts (11). However, in this study the increase in catalase activity in flies fed on Amaranth extract was not significant.

Oxidative stress is an important factor in the pathogenesis of many diseases (4). Several plant extracts with antioxidant activity have been shown to ameliorate effects of oxidative stress induced by compounds such as paraquat and hydrogen peroxide (19-23). The concentration of Amaranths that provides in vivo protection to oxidative stress does not significantly increase general in vivo antioxidant activity (DPPH scavenging activity) or the catalase enzyme activity. The protection, therefore, may be due to the interaction of the extract with other endogenous biochemical pathways which further studies could address.

In conclusion, our study demonstrates that the ethanolic extract of Amaranth leaves offer protection against hydrogen peroxide-induced oxidative stress in vivo in a dose dependent manner.

\section{Limitations}

These results are limited to male flies. Studies on female flies would provide more information on any gender related variations. Although Amaranths are widely consumed by humans, this study has been done in a lower invertebrate model and there is need for further testing in a vertebrate model before the results can be extrapolated to humans. The results are also limited to hydrogen peroxide induced oxidative stress and catalase enzyme. They cannot be used to draw conclusions on other antioxidant pathways.

\section{Abbreviations}

$\mathrm{H}_{2} \mathrm{O}_{2}$

Hydrogen peroxide; ASA:Ascorbic acid; NF:Normal Food; DPPH:2, 2, Diphenyl 1picrylhydrazyl

\section{Declarations}

\section{Ethical approval and consent to participate}

This was acquired from the Kampala International University Ethics and Scientific review board. Consent to participate was not applicable for this study.

\section{Availability of data and materials}

The datasets used and/or analysed during the current study are available from the corresponding author on request.

\section{Funding}


Not applicable

\section{Acknowledgements}

Authors wish to thank the assistance offered by Dr. Marta Vicente-Crespo for her technical support and Sayansi IxD and DrosAfrica that supported the establishment of the Institute of Biomedical Research at KIU with materials, equipment and training workshops. Furthermore, authors wish to acknowledge the support of Trend in Africa for their training on working with Drosophila melanogaster and manuscript writing. Finally we would like to acknowledge the assistance and support of Dr. Kenneth Iceland Kasozi, Mr. Oscar Asiimwe and Mr. Eliah Kwizera in the laboratory phase of the study.

\section{Consent to publish}

All authors have consented

\section{Competing interests}

The authors declare that they have no competing interests.

\section{Author's contribution}

HWK conceptualized the research, HWK and NJM designed the study, NJM collected the data; HWK and NJM conducted data analysis and interpretation.

\section{References}

1. Barros L, Ferreira MJ, Queirós B, Ferreira ICFR, Baptista P. Total phenols, ascorbic acid, $\beta$-carotene and lycopene in Portuguese wild edible mushrooms and their antioxidant activities. Food Chem. 2007;103(2):413-9.

2. Valko M, Leibfritz D, Moncol J, Cronin MTD, Mazur M, Telser J. Free radicals and antioxidants in normal physiological functions and human disease. Int J Biochem Cell Biol [Internet]. 2007 Jan [cited 2013 Aug 6];39(1):44-84. Available from: http://www.ncbi.nlm.nih.gov/pubmed/16978905

3. Pala FS, Kiymet T. Free radicals: Our enemies or friends? Funda Sibel Pala and K > ymet. Adv Mol Biol [Internet]. 2007;(1):63-8. Available from: https://acikerisim.iku.edu.tr/handle/11413/195

4. Rahal A, Kumar A, Singh V, Yadav B, Tiwari R, Chakraborty S, et al. Oxidative stress, prooxidants, and antioxidants: The interplay. Biomed Res Int. 2014;2014.

5. Sarangarajan R, Meera S, Rukkumani R, Sankar P, Anuradha G. Antioxidants: Friend or foe? Asian Pac J Trop Med. Elsevier B.V.; 2017;10(12):1111-6.

6. Muyonga JH, Nabakabya D, Nakimbugwe DN, Masinde D. Efforts to promote amaranth production and consumption in Uganda to fight malnutrition. In: Robertson GI, Lupien JR, editors. Using Food Science and Technology to Improved Nutrition and Promote National Development. International Union ofFood Science and Technology; 2008. p. 1-10. 
7. Kumar AB, Lakshman K, Jayaveera K, Khan S, Manoj B, Swamy NV. Evaluation of the Antioxidant Activity of Amaranthus spinosus. Sains Malaysiana. 2010;39(3):413-5.

8. Nana FW, Hilou A, Millogo JF, Nacoulma OG. Phytochemical Composition, Antioxidant and Xanthine Oxidase Inhibitory Activities of Amaranthus cruentus L. and Amaranthus hybridus L. Extracts. Pharmaceuticals [Internet]. 2012 Jun 15 [cited 2013 Aug 30];5(12):613-28. Available from: http://www.mdpi.com/1424-8247/5/6/613/

9. Pramanik P, Bhattacharjee R, Bhattacharyya S. Evaluation of in vitro Antioxidant Potential of Red Amaranth (Amaranthus tricolor) and Green Amaranth (Amaranthus viridis ) leaves extracted at different temperatures and pH. Ann Biol Sci. 2014;2(4):26-32.

10. Ashburner M, Golic KG, Hawley RS. Drosophila: A Laboratory Handbook. Second Edi. Cold Spring Harbor (New York): Cold Spring Harbor Laboratory Press.; 2005.

11. Alexander, Etuh M, C. Aguiyi J, Ogwu, Ochala S, Simeon O, Imoleayo, Oyeniran O, Debola OO, et al. The In vivo Antioxidant Protective Activity of Mangifera indica Cold Aqueous Leaf Extract in Drosophila Melanogaster. J Adv Biol Biotechnol. 2019;22(August):1-7.

12. Maina E, Kinyi HW, Ochwangi D, Meroka A, Wanyonyi W. Liver toxicity of Crude extract of Ficus natalensis traditionally used in South Western Uganda. African J Pharmacol Ther [Internet]. KE; 2013 Dec 31;3(4):116-21. Available from: http://journals.uonbi.ac.ke/ajpt/article/view/1257

13. Samarth RM, Panwar M, Kumar M, Soni A, Kumar M, Kumar A. Evaluation of antioxidant and radicalscavenging activities of certain radioprotective plant extracts. Food Chem. 2008;106(2):868-73.

14. Murthy G P, Leelaja B, Ravishankar H, Dharshan RC, Rajesh K. Evaluation of Neuroprotection and Antioxidant Activities viaDrosophila Model System in the Active Principle Derived from Sida glutinosa Comm. Ex Cav.-An Aboriginal Ethno-Medicinal Plant Drug Practiced in the Folklore Medicinal System. Biomed J Sci Tech Res. 2018;11(5):8855-62.

15. Iwase T, Tajima A, Sugimoto S, Okuda K, Hironaka I, Kamata Y. A Simple Assay for Measuring Catalase Activity: A Visual Approach. 2013;3-6.

16. Tiveron AP, Melo PS, Bergamaschi KB, Vieira TMFS, Arce MABR, Alencar SM. Antioxidant Activity of Brazilian Vegetables and Its Relation with Phenolic Composition. 2012;8943-57.

17. Kaur C, Kapoor HC. Anti-oxidant activity and total phenolic content of some Asian vegetables. Int J Food Sci Technol [Internet]. 2002 Feb;37(2):153-61. Available from: http://doi.wiley.com/10.1046/j.1365-2621.2002.00552.x

18. Katerere DR, Graziani G, Thembo KM, Nyazema NZ. Antioxidant activity of some African medicinal and dietary leafy African vegetables. 2012;1.

19. Attarde DL, Kadu SS, Chaudhari BJ, Kale SS, Bhamber RS. In vitro Antioxidant activity of Pericarp of Cucurbita maxima Duch . ex Lam. 2010;2(2):1533-8.

20. Niveditha S, Deepashree S, Ramesh SR, Shivanandappa T. Sex differences in oxidative stress resistance in relation to longevity in Drosophila melanogaster. J Comp Physiol B. 2017 Oct;187(7):899-909. 
21. Jordan KW, Craver KL, Magwire MM, Cubilla CE, Mackay TFC, Anholt RRH. Genome-wide association for sensitivity to chronic oxidative stress in Drosophila melanogaster. PLoS One. 2012;7(6).

22. Sadowska-Bartosz I, Bartosz G. Effect of Antioxidants Supplementation on Aging and Longevity. Biomed Res Int. 2014;2014:1-17.

23. Ajagun-Ogunleye MO, Adedeji AA, Vicente-Crespo M. Moringa oleifera Ameliorates Age-Related Memory Decline and Increases Endogenous Antioxidant Response in Drosophila melanogaster Exposed to Stress. Afr J Biomed Res. 2020;23(September 2020):397-406.

\section{Figures}

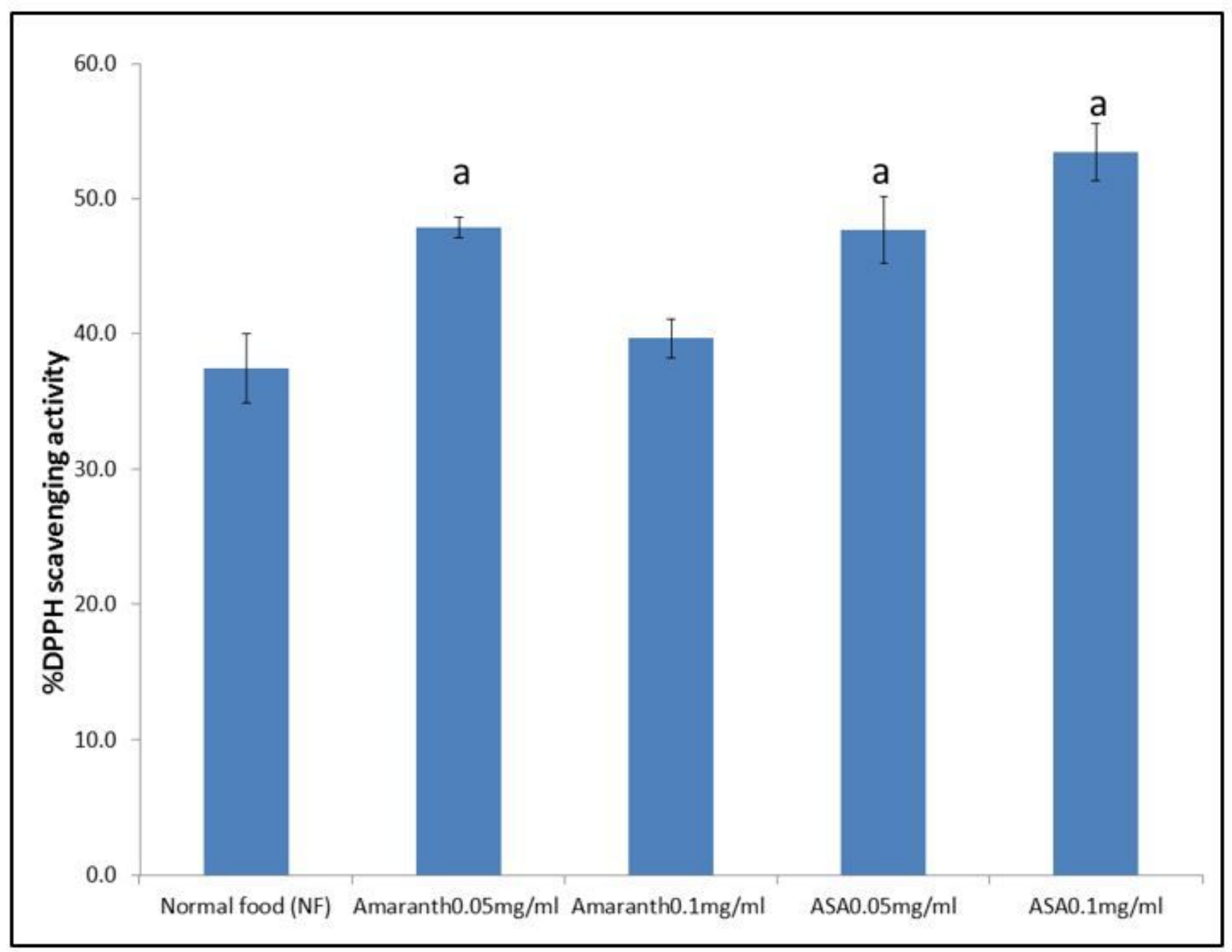

Figure 1

In vivo DPPH scavenging activity. Percentage DPPH scavenged by fly homogenates after feeding in experimental or control food for 5 days. a P< 0.05 (Tukey's vs normal food) 


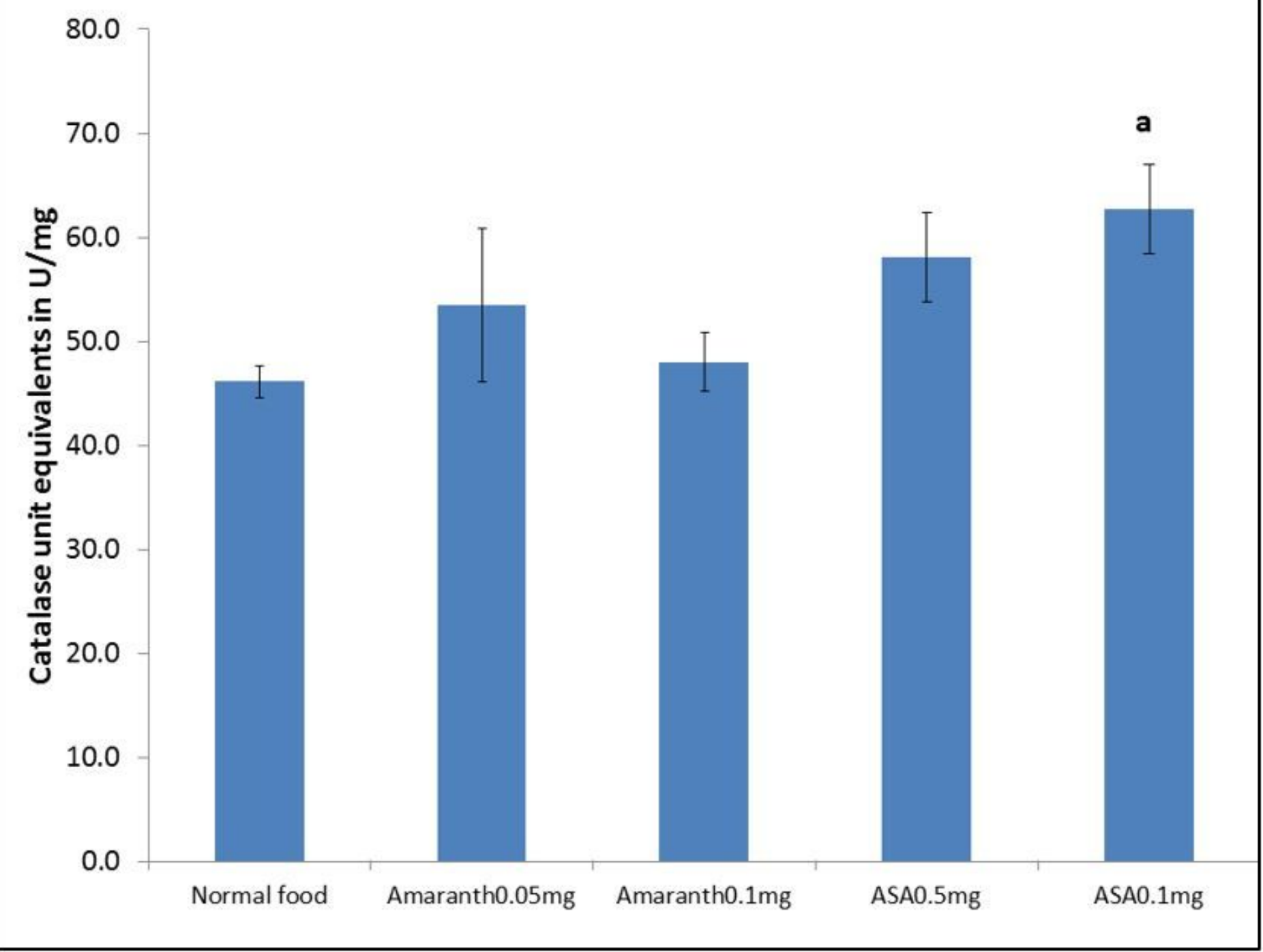

Figure 2

In vivo catalase activity. Catalase unit equivalents of fly homogenates after feeding in experimental or control food for 5 days. a P< 0.05 (Tukey's vs normal food) 


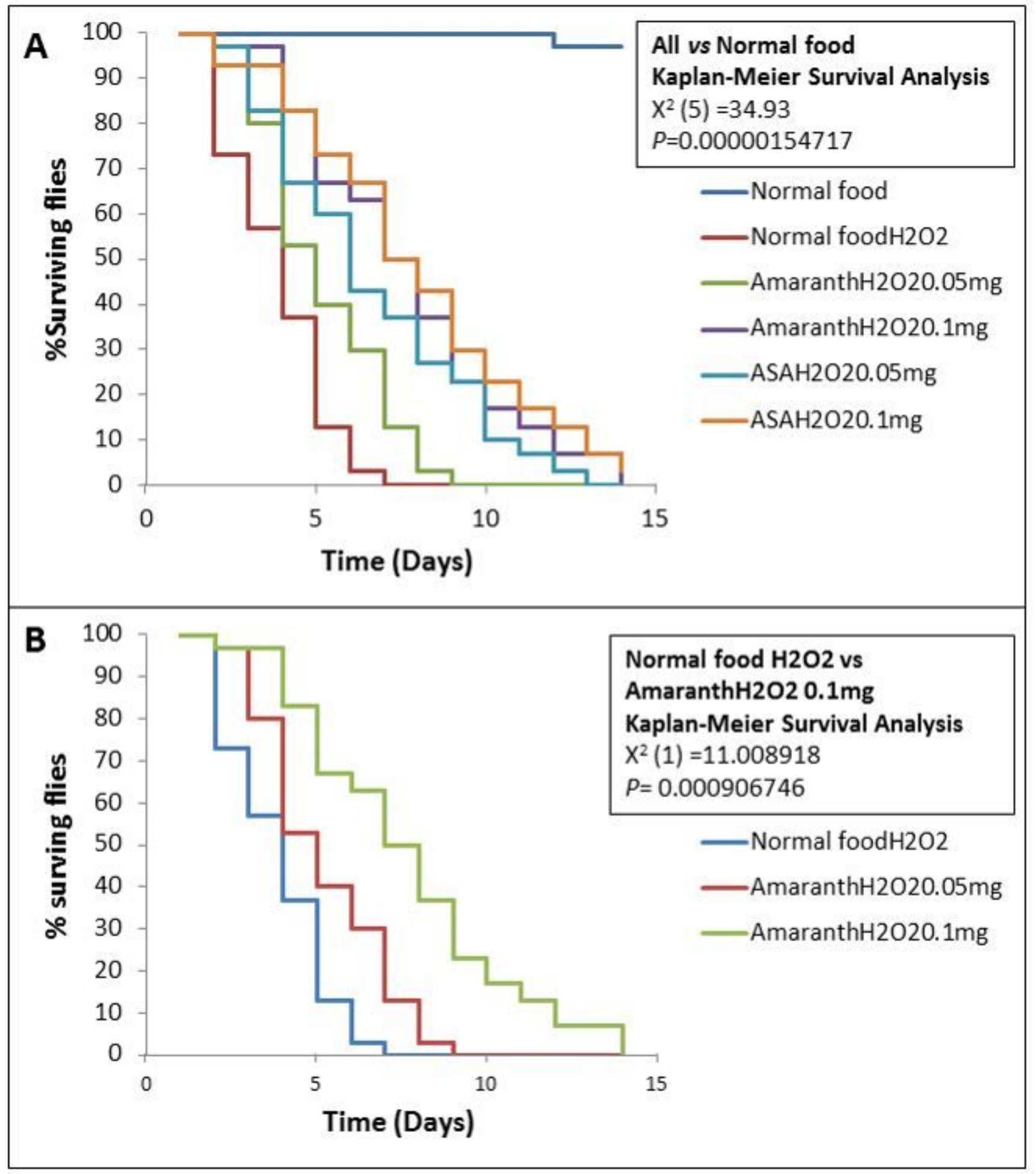

Figure 3

Survival of flies exposed to hydrogen peroxide. A) All flies exposed to hydrogen peroxide showed reduced survival. B) Supplementing food with $0.1 \mathrm{mg} / \mathrm{ml}$ of Amaranths for 5 days improved survival rate. 